\title{
Editorial
}

\author{
Nava Setter • Hermann Kohlstedt • Avner Rothschild • \\ Susan Trolier-McKinstry
}

Received: 1 April 2008 / Accepted: 2 April 2008 / Published online: 9 May 2008

(C) Springer Science + Business Media, LLC 2008

This special volume consists of papers presented at the ICE2007-International Conference of Electroceramics that was held at the foothills of Mt. Kilimanjaro, near Arusha, Tanzania on 31 July-2 August 2007. The Conference, with over 200 participants (among them some 60 invited speakers), covered diverse areas in the wide field of Electroceramics. After ICE2003 held in Boston, America and ICE2005 held in Seoul, Asia, holding the conference in Africa provided an exciting venue both to engage a different array of participants, and to help educate attendees on technology needs in the third world.

Scientists, researchers, postdocs, and students from six continents (North and South America, Asia, Europe, Oceania, and Africa) participated in this conference,

\footnotetext{
N. Setter $(\bowtie)$

Swiss Federal Institute of Technology,

Ecole Polytechnique Federale De Lausanne,

Ceramics Laboratory, Materials Department,

Lausanne CH-1015, Switzerland

e-mail: nava.setter@epfl.ch

H. Kohlstedt

FZ Jülich,

Jülich, Germany
A. Rothschild
Haifa, Israel

Technion-Israel Institute of Technology,

\section{S. Trolier-McKinstry}

The Pennsylvania State University,

Philadelphia, PA, USA
}

highlighting the worldwide interest in electroceramic materials. The Conference consisted of plenary lectures and technical sessions covering the following four key themes: (1) Electroceramics for energy, environment, and health, (2) electroceramics for informatics and communications, (3) processing and structural characterization of electroceramics, (4) properties and modeling of electroceramics. A special feature of the meeting was a number of micro-symposia on six focused 'hot' topics: electromechanical energy conversion, solid oxide fuel cells, oxide heterostructures, piezoelectric response enhancement, electroceramic memories, and electroceramic bulk-processing. In these symposia, invited experts presented recent advances and discussed some of the open issues in these fields. Another unusual event was a final session that was dedicated to Science Education at the high-school and university levels. It is a worldwide concern that many youth do not choose to study science and engineering while the progress of the world and the welfare of its inhabitants rely heavily on science and technology. High-school students with a science orientation from two high-schools in the Arusha region and their science teachers participated in this session. These students also had a tutorial on electroceramics previous to the beginning of the conference and participated in the opening plenary session. Two of the papers presented in the special session are included in this JECR volume.

We would like to acknowledge the financial support to the Conference by the European Science Foundation, the US National Science Foundation, and the EPFL-Swiss Federal Institute of Technology in Lausanne. 